\title{
Opportunities from low-resolution modelling of river morphology in remote parts of the world
}

\author{
M. Nones ${ }^{1}$, M. Guerrero ${ }^{2}$, and P. Ronco ${ }^{3}$ \\ ${ }^{1}$ Research Center for Constructions - Fluid Dynamics Unit, University of Bologna, Italy \\ ${ }^{2}$ Hydraulic Laboratory, University of Bologna, Italy \\ ${ }^{3}$ University of Padova, Department of Civil, Environmental and Architectural Engineering ICEA, Padova, Italy; \\ currently at Cà Foscari Venice University, Department of Environmental Sciences, Informatics and Statistics, \\ Venice, Italy
}

Correspondence to: M. Nones (michael.nones@unibo.it)

Received: 6 September 2013 - Published in Earth Surf. Dynam. Discuss.: 1 October 2013

Revised: 17 December 2013 - Accepted: 18 December 2013 - Published: 17 January 2014

\begin{abstract}
River morphodynamics are the result of a variety of processes, ranging from the typical small-scale of fluid mechanics (e.g. flow turbulence dissipation) to the large-scale of landscape evolution (e.g. fan deposition). However, problems inherent in the long-term modelling of large rivers derive from limited computational resources and the high level of process detail (i.e. spatial and temporal resolution). These modelling results depend on processes parameterization and calibrations based on detailed field data (e.g. initial morphology). Thus, for these cases, simplified tools are attractive. In this paper, a simplified 1-D approach is presented that is suited for modelling very large rivers. A synthetic description of the variations of cross-sections shapes is implemented on the basis of satellite images, typically also available for remote parts of the world. The model's flexibility is highlighted here by presenting two applications. In the first case, the model is used for analysing the long-term evolution of the lower Zambezi River (Africa) as it relates to the construction of two reservoirs for hydropower exploitation. In the second case, the same model is applied to study the evolution of the middle and lower Paraná River (Argentina), particularly in the context of climate variability. In both cases, having only basic data for boundary and initial conditions, the 1-D model provides results that are in agreement with past studies and therefore shows potential to be used to assist sediment management at the watershed scale or at boundaries of more detailed models.
\end{abstract}

\section{Introduction}

One-dimensional (1-D) models for river hydraulics simulations have been used since the 1970s by many agencies around the world dealing with water resources management and flood control. Aiming to describe the dynamics of free water surface and riverbed (i.e. bed level changes), a variety of open source and commercial 1-D codes has been realized. These models solve the equations of water flow and, in several cases, also the sediment continuity equation in the longitudinal direction. Among others, the HEC-RAS (Hydrologic Engineering Centers River Analysis System) by the US Army Corps of Engineers; the Full Equations (FEQ) model by the US Geological Survey; the Sedimentation and
River Hydraulics (SRH) 1-D by the US Bureau of Reclamation; the Telemac Mascaret 1-D by a European consortium based in France, Germany and the UK; the Mike11 by the Danish Hydraulic Institute; and the SOBEK 1-D by Deltares (NL) are well tested codes for river engineering that apply the 1-D longitudinal simplification. It is worth noting that, while open source codes have been optimized for specific applications (e.g. the FEQ is particularly suited for simulations of unsteady flow in open channel networks with a variety of control structures), commercial software packages have greatly improved to easily integrate detailed data from geographic information systems (GIS) and boundary conditions from climate-hydrology models and for downscaling to more detailed simulations (i.e. 2-D and 3-D models). Albeit 
in the last decades 1-D and 2-D codes have been provided with modelling of bed level changes to be coupled with hydraulic computations, the simulation of large rivers at the watershed scale remains a difficult task because of the involved space and time lengths, which are within $10^{2}$ and $10^{3}$ kilometres and years, respectively (Di Silvio and Nones, 2013).

Sediment management of large rivers is particularly relevant when evaluating damming or climate change impacts, for instance. This is most challenging in remote parts of the world, where frequent and detailed topographic surveys of river cross sections are uncommon and which may largely limit the application of detailed numerical codes. While conventional 1-D and 2-D morphodynamic models require detailed inputs describing initial morphology and boundary conditions, the model proposed here is able to describe the longitudinal evolution of a river reach at non-detailed spatial and temporal scales by using a basic database. To reduce the computational effort and simulation results dependence on field data (e.g. river channel bathymetry, detailed spatial distribution of alluvial deposition), a series of testable simplifications are introduced in the hydraulic equations, such as the kinematic propagation of the water flow and the local uniform flow (LUF) hypothesis (Fasolato et al., 2011). Under these assumptions, it is possible to simulate riverbed dynamics by implementing a simplified description of the river morphology, which can be derived from maps and satellite images. The use of satellite images and digital terrain models (DTMs) rather than detailed topographic surveys noticeably extends the 1-D model applicability to large rivers in undeveloped countries by drastically reducing modelling efforts and results that depend on detailed field data (Ronco et al., 2010; Nones, 2013).

Two applications of this simplified 1-D code are presented here. These case studies show the 1-D model's performance in providing long-term predictions to support sediment management in large rivers, which is related to natural and anthropogenic pressures (e.g. climate variation, hydropower exploitation). Given the lack of detailed and extensive data for remote parts of the world, the simplified model can substitute and/or support multi-parameter 2-D modelling of river watersheds (Coulthard and Van de Wiel, 2013) or be coupled to detailed 2-D modelling of some river features (e.g. junctions and bifurcations), such as the typical downscaling approach used in Guerrero et al. (2013b). 2-D modelling requires detailed field data for accurate calibrations and validations, which fix a model's parameters and therefore influence the reliability of the results (Guerrero and Lamberti, 2013; Guerrero et al., 2013a; Williams et al., 2013). The model applied here avoids these limitations by coupling a 1-D hydro-morphodynamic model (physicallybased on water flow and riverbed profile equations) with a cross-sections sub-model. The 1-D model simulates the riverbed aggradation-degradation rate and the corresponding sediment sorting along the watercourse, although at non- detailed scale, while the sub-model describes the empirical relationship between river width and hydrological cycle.

This contribution aims to demonstrate the potential of nondetailed models for analysing the long-term impact of anthropogenic and natural pressures, especially in the case of large rivers in remote parts of the world where detailed field data are usually not available for the calibration of high-resolution models.

\section{Case studies}

The first application concerns a lower branch of the Zambezi River (Africa) that has been regulated by the construction of various dams during the last century. These dams strongly modify the natural pattern of flow variations in time and quantity (Suschka and Napica, 1986; McCartney et al., 2013). Several authors have studied the impact of the two major reservoirs (namely, Kariba and Cahora Bassa dams) on the Zambezi River system. Most of them focused on the biological, ecological and economical effects (biodiversity, fisheries, wetlands, etc.) of these reservoirs (Bowmaker, 1960; Attwell, 1970; Hall et al., 1977; Du Toit, 1984; Dunham, 1989; Beilfuss and Davies, 1999; Beilfuss et al., 2001; Scodanibbio and Mañez, 2005; Tilmant et al., 2012; McCartney et al., 2013). Fewer works addressed morphological changes correlated to the dams' impacts on sediment and water discharges (Guy 1981; Suschka and Napica, 1986; Beilfuss and Davies, 1999; Davies et al., 2000; Basson, 2004; Ronco et al., 2010; Brown and King, 2012; Nones et al., 2013). These two major dams have noticeably changed the hydrological cycle of the lower Zambezi River. Data collected at the gauging station of Tete (Mozambique, about $135 \mathrm{~km}$ downstream of Cahora Bassa) show a modified pattern of monthly runoff characterized by the increase of minimum and decrease of maximum values (Ronco, 2008; Ronco et al., 2010). As far as the effects on river morphology are concerned, some authors have evaluated changes of the lower part of the Zambezi after the dams' construction (Suschka and Napica, 1986; Beilfuss and Davies, 1999; Davies et al., 2000; Ronco et al., 2010). The removal of sediments from gorge sections, the stabilization of braids and bars in some sections and of an individual channel in others, the delta erosion and the concurrent increase of salt-water intrusion have all been attributed to these impoundments (Chenje, 2000). Unfortunately, no systematic, detailed surveys of observed morphological changes are reported in the literature, which might have been applied to validate a detailed 2-D model. As an alternative, a simplified 1-D modelling was performed on the basis of the riverbed profile before damming, river stage records, a few sedimentological samples and available satellite images.

The second application addresses climate variability's effectiveness in modifying the morphology of the middle and lower Paraná River reaches in Argentina. Amsler et al. (2005) and Castro et al. (2007) analysed how the 
streamflow variation has affected the Paraná morphology at its middle and lower reaches, respectively, during the 20th century. These authors related the climate inter-decadal variability to the discharge values most effectively modifying morphology (namely, the effective discharge) and, as a consequence, to river morphological changes observed. In particular, Amsler at al. (2005) observed that the dry midst of the last century (1930-1970) was characterized by low effective discharge, which promoted a decrease in width, braided index, thalweg sinuosity, width-to-depth ratio and channel volume in the middle Paranà, with opposite patterns found in the beginning and end of the same century. Differently, Castro et al. (2007) investigated the lower Paranà morphology and pointed out that it was not as straightforwardly correlated to the hydrological variability as was the middle Paranà. In particular, a continuous and progressive oversimplification of the river channel planimetric morphology toward a smaller width-to-depth ratio was observed regardless of the oscillation in hydrology that had occurred. Reasons for these different responses to the same climate variabilities were found in alluvial plains, which noticeably enlarged and degraded when passing from the middle to the lower Paranà. These morphological constraints, together with the driving increase of precipitations during the latter part of the 20th century, would have produced sediment deposition at secondary reaches and therefore the streamflow gathering in a single straight and deep reach. Although these channel divagations can be simulated with a 2-D morphodynamic model, the large-scale morphology (i.e. river slope and width, sediment sorting) was modelled by means of a simplified 1$\mathrm{D}$ code. Thus, in this study, the combined effects of climate variation and morphological constraints during the 20th and 21st centuries were simulated for the middle and lower Paranà. Future hydrology was computed by applying four climate scenarios spanning the period 1991-2098, which were provided from different combinations of global and regional climate models (Saurral et al., 2013). A significant increase of the effective discharge and flow-discharge variability can be observed passing from the 20th century time series to forecasts, which slightly increases the rate of change of riverbed levels. However, the bed profile appears rather stable, confirming that the present river-alluvial slopes will remain fixed constraints to channel divagation.

\subsection{The Zambezi River}

The Zambezi River (Fig. 1) is the fourth-longest river in Africa, with a basin of about $1.4 \times 10^{6} \mathrm{~km}^{2}$. This river, with a total length of about $2574 \mathrm{~km}$, has its source in Zambia and flows through Angola, along the borders of Namibia, Botswana, Zambia and Zimbabwe, to Mozambique. The Zambezi system can be subdivided into three reaches, each differing in its geological template, biodiversity and landscape characteristics: the upper, middle and lower Zambezi (Hughes and Hughes, 1992; Main, 1992; Timberlake, 1998).
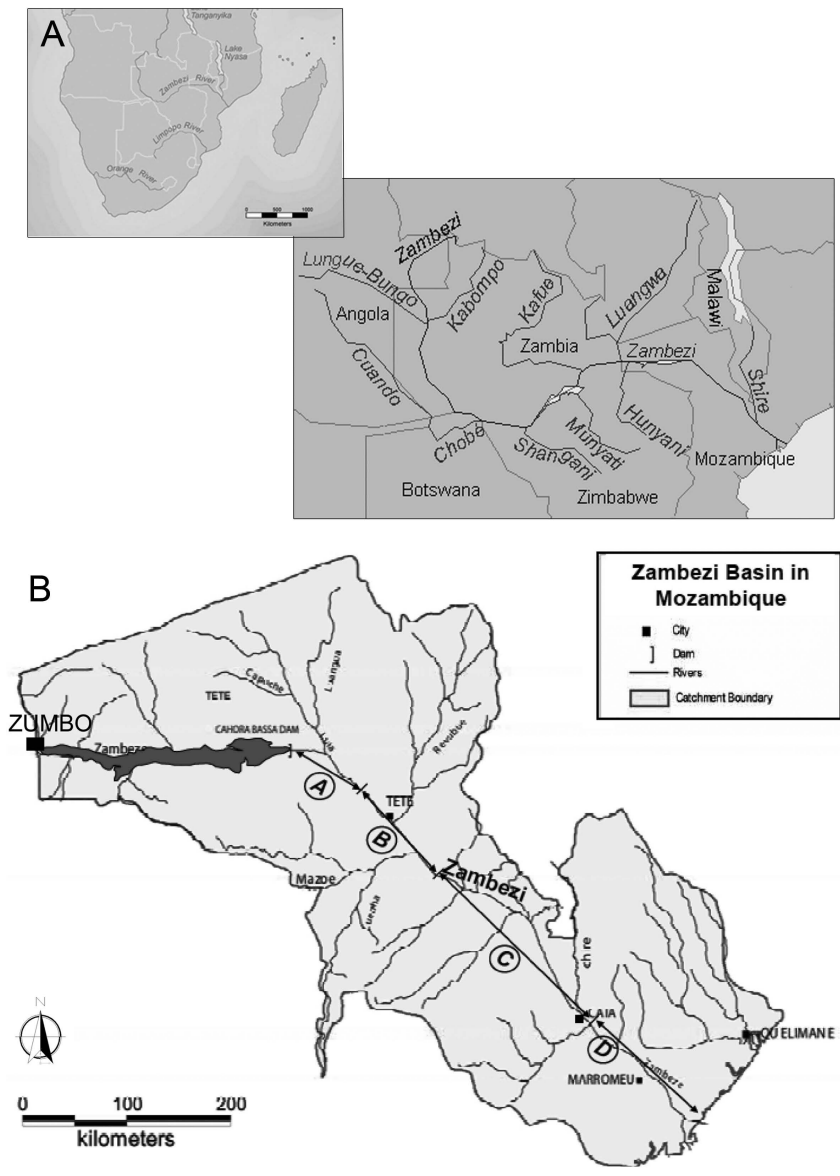

C

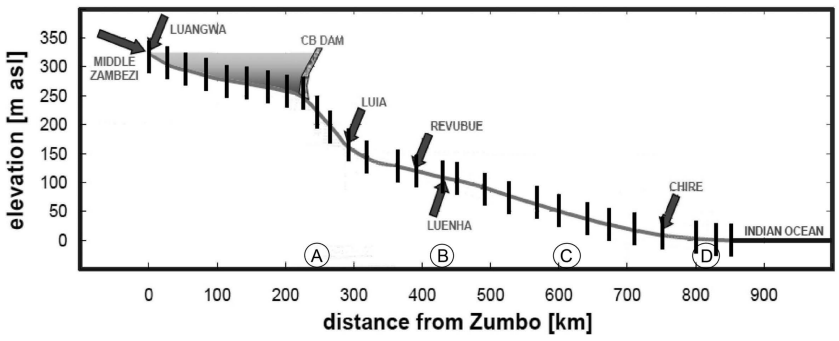

Figure 1. (A) Main African rivers' basin, focus on the Zambezi River. (B) Lower Zambezi downstream the Cahora Bassa Dam. (C) Long profile of the main channel and principle tributaries of the lower reach (adapted from Ronco et al., 2010).

The upper Zambezi flows through Angola and Zambia for about $1500 \mathrm{~km}$. The Victoria Falls represent the boundary between the upper and middle reaches. About $240 \mathrm{~km}$ downstream of the Victoria Falls, the river flows into the Kariba Lake, created in 1959 by the Kariba Dam, which has a storage capacity of $180.6 \times 10^{9} \mathrm{~m}^{3}$ (Reeve, 1960; Davies et al., 2000). The middle Zambezi flows into the Cahora Bassa Lake (Mozambique), which has a storage capacity $\left(72.5 \times 10^{9} \mathrm{~m}^{3}, \mathrm{HCB}, 2004\right)$ resulting from the construction of the Cahora Bassa Dam in 1974. The lower Zambezi 

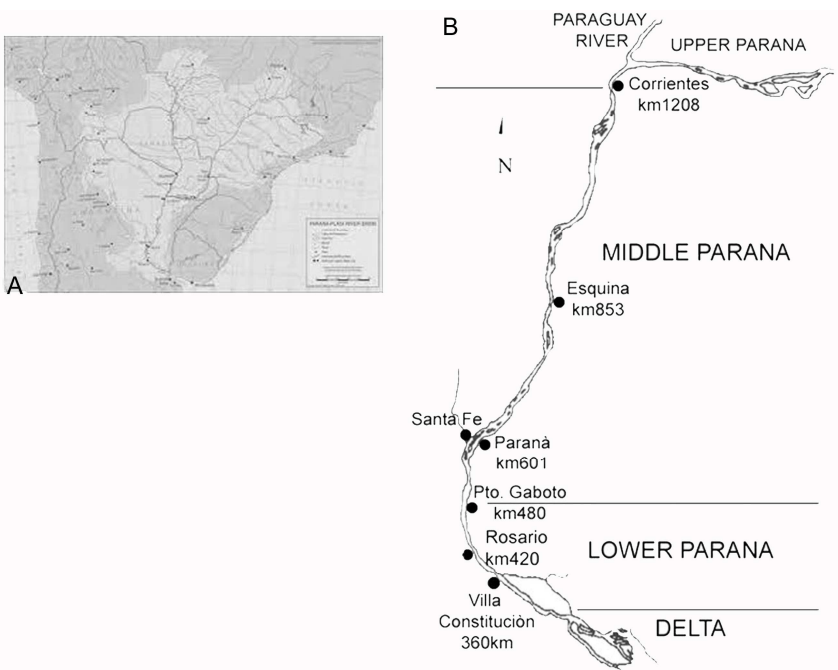

Figure 2. (A) La Plata Basin. (B) The middle and lower Paraná with the principal cities and corresponding kilometric labelling of the water way.

is about $650 \mathrm{~km}$ long, reaching from the Cahora Bassa Lake to the Indian Ocean. This reach is characterized by a broad floodplain, with parallel channels and shifting sandbanks, while the coastal portion includes extensive grasslands and freshwater swamps, dunes and mangroves (Timberlake, 1998).

As reported in Ronco (2008), the construction of these two dams has considerably changed the hydrological cycles in the lower Zambezi: effective discharge downstream Cahora Bassa has decreased from around $3500 \mathrm{~m}^{3} \mathrm{~s}^{-1}$ during the $1950 \mathrm{~s}$ to around $1800 \mathrm{~m}^{3} \mathrm{~s}^{-1}$ during the 1990s. Some authors (Bolton, 1983; Walling, 1984; Walford et al., 2005) have estimated sediment yield of the Zambezi within the range of $10-20 \times 10^{6} \mathrm{t} \mathrm{yr}^{-1}$, by means of observed delta modifications and sedimentary records.

\subsection{The Paraná River}

The Paraná River, with a watershed of about $2.6 \times 10^{6} \mathrm{~km}^{2}$, is the most important tributary of the La Plata Basin (LPB), which has a basin of $3.2 \times 10^{6} \mathrm{~km}^{2}$ within Argentina, Brazil, Paraguay, Uruguay and Bolivia, and outflows into the Atlantic Ocean near Buenos Aires (Fig. 2a). Figure 2b reports the studied river reaches from Corrientes to Villa Constitución, (i.e. the middle and lower Paraná) with main cities and their kilometric labels along the water way.

The middle and lower Paraná reaches flow from north to south through Argentina for about $1000 \mathrm{~km}$; the mean annual discharge is around $12000-15000 \mathrm{~m}^{3} \mathrm{~s}^{-1}$ and the total sediment transport is around $130-135 \times 10^{6} \mathrm{t} \mathrm{yr}^{-1}$ (Amsler et al., 2005). The Paraguay River joins the Paraná just upstream the city of Corrientes. No other significant tributaries that supply water and sediments are present downstream of this confluence (Amsler and Drago, 2009).

The middle and lower Paraná play a significant role in the LPB's sediment transport and morphodynamics. Clay and silt materials, coming from the Bermejo River (a tributary that flows from northern Argentina), represent around $80 \%$ of the total solid discharge and are transported as wash load to the Paraná delta and large wetlands during flood periods. The remaining $20 \%$ (around 20-25 $\times 10^{6} \mathrm{t} \mathrm{yr}^{-1}$ ) is fine sand, which is transported as bed- and suspended-load, modifying the river morphology. The channel bed is composed mostly of fine and medium sand, and its planform pattern is classified as anabranching with meandering thalweg (Latrubesse, 2008). In planform, a succession of wider and narrower nodal sections is observed, with mean channel widths and depths ranging from $600-2500 \mathrm{~m}$ and from $5-16 \mathrm{~m}$, respectively.

\section{Methods}

\subsection{1-D mathematical modelling}

The 1-D model applied here was firstly developed a few years ago by Di Silvio and Peviani (1989) to analyse the longitudinal evolution (i.e. variations of bed profile, grain size composition and sediment transport) of small rivers at watershed scale. Conventional 1-D morphological models require a detailed description of river geometry. On the contrary, the applied code couples the 1-D equations of water flow with the sediment continuity ones (namely, the De St. Venant Eq. and the Exner and Hirano (1971), reported below) to describe the longitudinal evolution of a river reach at non-detailed scales.

$\frac{\partial Q}{\partial x}+\frac{\partial A}{\partial t}=0$

$\frac{\partial}{\partial x}\left[H+Z+\frac{Q^{2}}{2 g \cdot A^{2}}\right]=-\frac{1}{g} \cdot \frac{\partial U}{\partial t}-J$

$\sum_{i=1}^{N} \frac{\partial G s_{i}}{\partial x}=-B \cdot \frac{\partial Z}{\partial t}$

In these equations, $Q$ is the river discharge, $A$ represents the wetted area of the channel, having depth $H$ and width $B, Z$ is the bottom elevation, $U$ indicates the current velocity and $G_{\mathrm{Si}}$ is the solid discharge of the $i$ th grain size class.

To reduce the computational effort, a series of acceptable simplifications are introduced in the hydraulic equations, such as the local uniform flow (LUF) hypothesis (Fasolato et al., 2011) and the kinematic propagation of water flow. Under the LUF hypothesis, the energy line, water and bed profiles have the same slope, and the variation of the longitudinal bottom elevation $\partial Z / \partial x$, computed by Eq. (2), depends only on the slope of the energy line $J$ (Eq. 5). This equation 

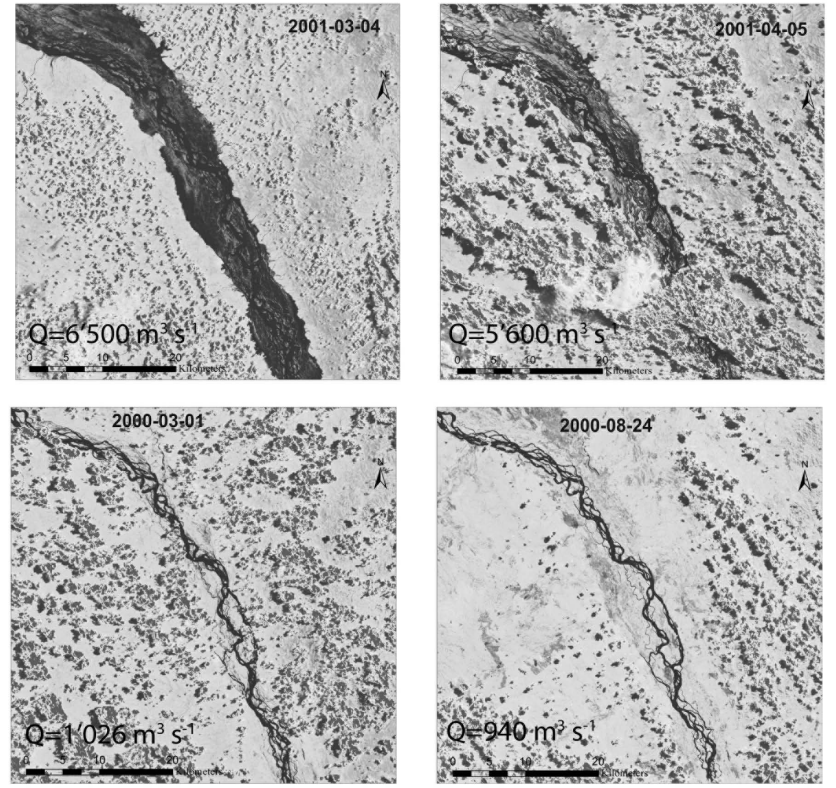

Figure 3. Example of satellite images of the lower Zambezi River upstream Caia (Mozambique): variation of the active river width related to the variation of the river discharge. Discharges vary between $6500 \mathrm{~m}^{3} \mathrm{~s}^{-1}$ and $940 \mathrm{~m}^{3} \mathrm{~s}^{-1}$.

is applied to describe the bed profile evolution by modelling the water profile at appropriate length $X$ and duration scales $\tau$. The spatial and temporal scales, respectively called "morphological box" and "evolution window", are functions of the Froude number of the current (Ronco et al., 2009; Fasolato et al., 2011). It is worth noting that the Local Uniform Flow Morphodynamic (LUFM) model was implemented for long-term analyses that on average fulfil the applied simplifications. In fact, modelled river features are averaged over a relative long period $\tau$ (i.e. time window), which was fixed to one year for both performed studies on the basis of resulting Froude numbers. The Eqs. (1-3) respectively become

$\frac{\mathrm{d} Q}{\mathrm{~d} X}=0$,

$\frac{\mathrm{d} Z}{\mathrm{~d} X}=-J$

$\sum_{i=1}^{N} \frac{\mathrm{d} G s_{i}}{d X}=-B \cdot \frac{\mathrm{d} Z}{\mathrm{~d} \tau}$.

The sediment transport formula, Eq. (7), applied in the model is derived from the Engelund-Hansen formula for computing the bed- plus suspended-load (i.e. total-load), as described in Ronco (2008) and Nones (2013). In Eq. (7) the rate of bed and suspended sediment transport at yearly scale, $G_{\mathrm{s}}(\tau)$, depends on energy slope (corresponding to water and bed slopes under the LUF hypothesis), $J(\tau)$, active width, $B(\tau)$, sediment mean diameter, $\mathrm{d}(\tau)$, and effective discharge, $Q_{\text {eff }}(\tau)$, at each morphological box (around $50-80 \mathrm{~km}$ for both studies, depending on the Froude number):

$G_{\mathrm{s}}(\tau)=\alpha^{\prime} \cdot\left[\frac{Q_{\mathrm{eff}}(\tau)^{m} \cdot J(\tau)^{n}}{B(\tau)^{p} \cdot \mathrm{d}(\tau)^{q}}\right]$.

The active cross section is defined as the river channel width that conveys the annual sediment transport, except for wash load (Ronco et al., 2009; Nones, 2013). The effective discharge defines the flow that cumulates most of channel sediments (Biedenharn et al., 1999), i.e. following the Schaffernak approach (Garde and Ranga Raju, 1977), the maximum value of the product of interval frequencies $f r$ with solid discharges $G_{\mathrm{s}}$ occurring in the interval as assessed for corresponding hydrological conditions. The coefficient $\alpha^{\prime}$ and the exponent $m$ were calibrated by assuming the long-term equilibrium between measured effective discharge and sediment transport rate, while other exponents used in Eq. (7) are functions of $m$. More details on these parameters and their computation can be found in Di Silvio (1983, 2004).

The initial river widths, $B(\tau=0)$, were derived from satellite images and the initial slopes, $J(\tau=0)$, from lowresolution topography (i.e. watershed cartography, DTMs), while sediment distributions were available from some samples taken along the river. Such a basic database is usually also available for remote parts of the world, which noticeably extends the model applicability to large rivers with respect to more advanced 2-D codes.

In order to describe the seasonal widening and narrowing of river sections, a basic calibration method was introduced that combines satellite images with flow discharge records. The 1-D model was coupled to a simplified description of river cross sections (explained in detail in Nones, 2013), which accounts for river width changing at a smaller timescale (i.e. seasonal oscillation) with respect to the bed level evolution simulated. This synthetic crosssections model (Eq. 8) computes the active river width as a function of the flow discharge. Indeed, the statistical distribution of river width $B(\delta)$ was expressed by means of the statistical distribution of water discharges $Q(\delta)$, where $\delta$ is the event occurrence frequency at the analysed section and during the calibration period (i.e. 2000-2010 for both applications). Thus, for discharges lower than the bankfull value (the minimal discharge flowing over alluvial plains), an ata-site hydraulic geometry relationship was assumed (Eq. 8) for the synthetic description of active cross sections (Singh, 2003):

$B(\delta)=\alpha \cdot Q(\delta)^{\beta}$

where $\alpha$ and $\beta$ are the calibration parameters (see, e.g. Leopold and Maddock, 1953; Yalin, 1992; Parker et al., 2007; Wilkerson and Parker, 2011; Nones, 2013). The river 
widths for the calibration period were obtained from Landsat 7 satellite images (USGS database), which have a resolution of $15 \mathrm{~m}$. The corresponding discharges were derived from the available river stage records. Images corresponding to flood events were discarded; in those cases, wetted areas did not provide evidence of the active channel geometry but the flooding (Fig. 3).

The LUFM model simulates the evolution of the riverbed profile, which is driven by the fluvial sediment transport. The investigated dynamics were uncoupled from the geological processes (namely, from the LGM, Last Glacial Maximum, to present day) and also from the floodplains transport. The assumption of fixed floodplains is justified by their very slow evolution. Indeed, finest sediment, transported as wash load, has been cumulated in the alluvial plain during flood events recurring over thousands of years, while the active channel morphology was noticeably modified within a few decades.

\subsection{Model reliability}

Albeit the validation of the proposed model is not within the objectives of this study, a short summary of past works about the application of the LUFM model to gauged watersheds is reported for the convenience of readers.

A first version of the LUFM model was applied to the gauged basins of small rivers located in Italy, such as the Adige River (Nones et al., 2009), the Mallero River (Di Silvio and Peviani, 1989) and the Piave River (Fasolato et al., 2006). This version, assuming that the river width remains constant with time, computed reliable evolutions of the rivers, also by introducing anthropogenic forcing terms (e.g. dredging operations, dams, land use changes).

In the case of the Piave River, the LUFM model was used to analyse the morphology of the river due to flushing operations. A comparison between the measured turbidity values and the computed sediment transport highlighted the reliability of the model to reproduce the periodic flushing peaks. The deposition of sediments downstream of the impoundment and the reduction of the grain size are quite well reproduced, notwithstanding the few available input data.

In the case of the Adige River, the model was applied to analyse the major anthropogenic changes that have occurred during the past century, relating to the reduction of sediment transport due to soil-protection interventions, derivations for industrial and agricultural uses, changes in the duration curve of flow discharge, interception of solid material by hydropower reservoirs, and extraction of fluvial sediments by means of quarries. The results of the LUFM model confirmed (1) the decreasing of sediment transport observed after 1920, chiefly due to the construction of various hydropower plants in the Adige's basin, and (2) the bed erosion in the lower part of the river caused by quarry activities.

The studied rivers have been intensively studied and monitored since the beginning of the past century, which has provided a valuable matching to verify the model reliabil- ity with a strict comparison between the computed results and the available measured values. These validations have highlighted a good correlation between model results and the available rich data set from the literature, despite the basic description that is required as input.

\section{Results}

\subsection{Evolution of the Zambezi River during the 20th century}

The present paper summarizes the major results of a LUFM model's application to the unsurveyed lower Zambezi River basin published in Ronco et al. (2010) and Nones et al. (2013). The application simulated the morphological behaviour of the lower Zambezi starting from 1907, when first systematic measurements were recorded at the gauging station of Zumbo, Mozambique (Fig. 1b). These measurements were analysed to assess the effective discharge of lower Zambezi and its main tributaries, together with the corresponding sediment input, during the 20th century. The data were applied at model boundaries and for characterizing river widthdischarge relationship along the simulated reach. The turbidity measurements performed by Hall et al. (1977) have been utilized for the calibration of the transport formula (Eq. 7), as reported in Ronco et al. (2010).

The mentioned previous simulations performed with the LUFM model on the lower Zambezi River did not considered river width-discharge relationship (Ronco, 2008; Ronco et al., 2010). For that case, the model results show an enduring process of sediment deposition, which slowly propagates downstream. The long-term evolution was apparently dominant with respect to the recent evolution related to the dams' constructions.

The computations reported here also accounted for seasonal oscillations, which simulated river widening and narrowing. These simulations confirmed the previous results: the lower reach presents a widespread tendency to a progressive deposition, especially in the flat zones downstream of the gorges, where some tributaries flow into the main channel (Fig. 1c). This trend was affected by the two reservoirs to some degree (Nones et al., 2013). Dams trap sediments, which slowly modify riverbed morphology and corresponding bed composition. In more detail, the undisturbed river aggradation corresponded to a progressive fining of riverbed sediments. In the cases of dams' implementations, two opposite effects altered the natural process, yielding a more stable bed: (1) the water flow reduction rapidly propagates downstream, with important implications for the local ecosystem; and (2) the sediment sorting is delayed because of trapping (Ronco et al., 2010; Nones et al., 2013).

The simplified modelling of cross-sections changes at seasonal timescale bore out a typical evolution from braided to unicursal morphology (Leopold and Wolman, 1957; Nones, 2013). The simulated flow decreasing because of water 

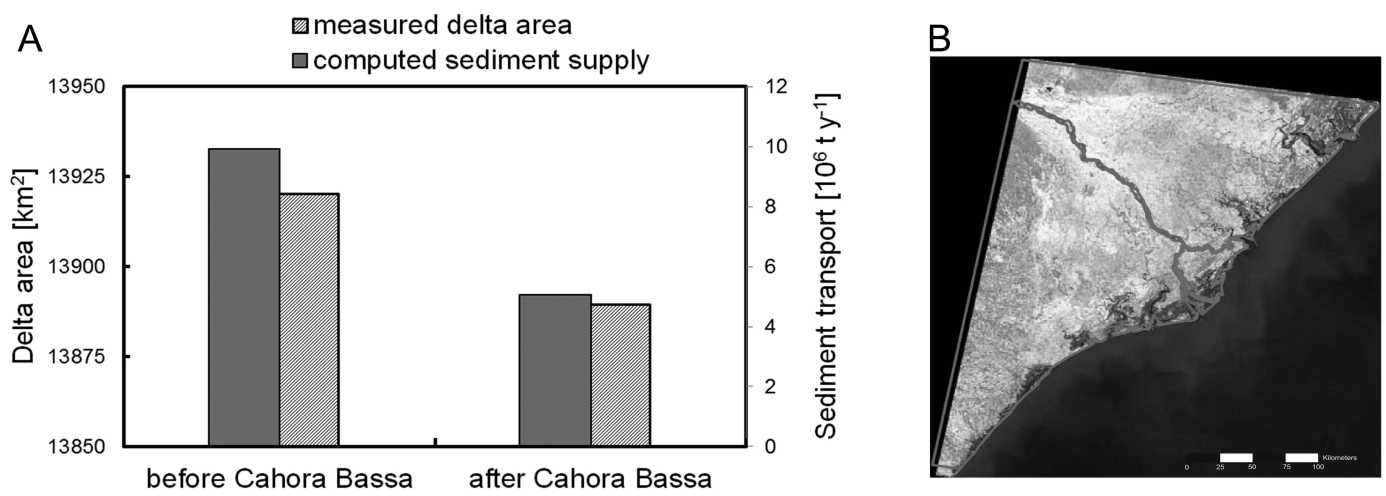

Figure 4. (A) Averaged values of the simulated sediment yield and the measured evolution of the Zambezi Delta from satellite images, before and after the construction of the Cahora Bassa Dam. (B) Satellite image of the Zambezi Delta (USGS database, 2013).

impounded in the reservoirs corresponded to narrowing of active cross sections. This simplified modification of crosssections shapes reflects the observed tendency to unicursal morphology and accretion of vegetated floodplains, which limits channel divagations. In other words, lower flows were simulated with sections narrowing, which agree with the observations of vegetation density increase and abandoned secondary channels. This behaviour was also reported by Davies et al. (2000) and Nones et al. (2013).

The performed simulations also gave multiple evidence on the delta shoreline evolution (Fig. 4), which has been recognized as a key indicator of sediment yield in various large rivers of the world. This evolution was evaluated on the basis of seven satellite images (from the USGS's database) spanning the period 1970-2013, which confirmed the general negative trend of the delta surface extension (Ronco, 2008; Ronco et al, 2010; Nones et al., 2013). Figure 4a shows the negative trend after the construction of the Cahora Bassa Dam. In total, erosions prevailed yielding a loss of the delta area of around $50 \mathrm{~km}^{2}$ in the analysed period. The simulated time series of sediment transport rate in the most downstream morphological box confirmed the observed erosional trend for the Zambezi's delta. In fact, this time series reflects the historical sediment supply to the delta. The simulated rate of sediment transport appeared correlated to the observed variation of the delta area (Fig. 4b), notwithstanding that the satellite images used may be affected by occasional changes in water level and that the shoreline morphology is also affected by the Indian Ocean dynamics (Ronco et al., 2010). More detailed analyses, also with a specific model able to simulate the long-shore drift, are necessary for a thorough characterization of the delta's dynamics.

\subsection{Evolution of the Paraná River during the 20th and the 21 st centuries}

In this case, outputs from four regional climate models (RCMs) were used to produce future hydrological scenar- ios at the La Plata Basin. These scenarios were prescribed as boundary conditions for the performed modelling, covered much of the 21 st century and were provided by the research project "A Europe-South America Network for Climate Change Assessment and Impact Studies in La Plata Basin" (CLARIS-LPB). Specifically, the four RCMs are (1) PROMES (UCLM, Spain) covering the period 1991-2098, (2) RCA (SMHI, Sweden) for 1981-2098, (3) RegCM3 (USP, Brazil) having information for period 1981-2048, and (4) LMDZ (IPSL, France) with information for period 19912048. In addition, the 20th century scenario was produced from climatology-hydrology records. The details on these data sets are reported in Saurral et al. (2013). Figure 5 shows a comparison of the different applied scenarios in terms of frequency distribution of monthly flow discharges at Corrientes, which is the upstream boundary of the Paraná reach simulated by means of the LUFM model. It is possible to observe a relatively large dispersion among the different RCMs and a general increase in the frequency of large discharges for predictions with respect to the past century, which is particularly evident for the RegCM3 scenario.

As reported in the literature (Amsler et al., 2007), the alluvial plains morphology changes take place over a longer timescale (geological periods) and are affected by finest sediment (wash load) deposition only during floods recurring in thousands of years time frames. The LUFM model computed the sediment transport in the river channel, i.e. the effective discharges that form the channel morphology over decades, while flooding discharges were disregarded. Actually, the wash load was not computed by the model, but it may also affect the delta growth.

The literature data regarding the middle and lower Paraná River morphology at watershed scale mostly concern the transported sediment volume per year and the corresponding most effective discharge in conveying this volume at some sections (Amsler et al., 2005; Castro et al., 2007). Thus, the LUFM model results were used to assess sediment volumes per year and corresponding effective discharges for future 


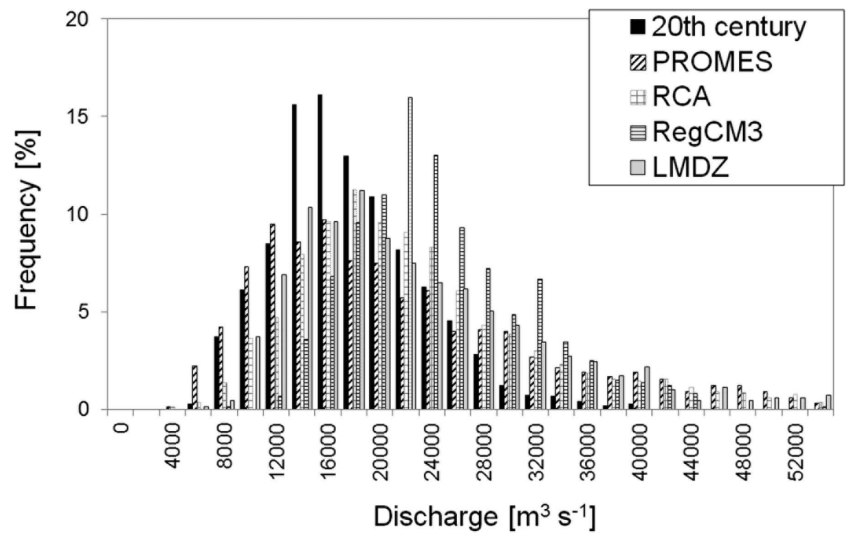

Figure 5. Frequency distributions of monthly flow discharges of applied scenarios for LUFM modelling (20th century and future prediction from listed RCMs) at Corrientes.

and past scenarios. The average effective discharges for each decade of the 20th century from the literature compared to LUFM corresponding results show a good correlation with maximum deviations in the order of a few per cent, with few exceptions for the largest discharges. As input data, the 1$\mathrm{D}$ model uses river discharge with $1 \mathrm{yr}$ time step, while the literature data are referred to as monthly discharges. Yearly values can be representative of the averaged morphological variations of the channel due to the inter-decadal variability, with a reduction of the computational effort. Flooding events, which have a duration of 1-2 months, were considered unimportant for the morphological evolution of the Paraná River because of their temporal scale (months) with respect to the morphological changes (years).

According to the Schaffernak approach, the sediment volume per year was divided into discharge classes of $2000 \mathrm{~m}^{3} \mathrm{~s}^{-1}$ width and was compared among the scenarios (Fig. 6). For any analysed scenario, the average volume per year was almost the same (changing within the range of $20-30 \times 10^{6} \mathrm{tyr}^{-1}$ ), but the distributions among the classes resulted rather differently. The distribution for the 20th century did not present a very high, recognizable maximum. The highest sediments volume was conveyed by the flow discharge interval of $13000-17000 \mathrm{~m}^{3} \mathrm{~s}^{-1}$ (i.e. the average effective discharge per year for the 20th century), which roughly agrees with the Amsler et al. (2005) investigation. Using records from last century's water levels and monthly flow discharges in Corrientes, Amsler et al. (2005) assessed the effective discharge to vary within the $15400-24500 \mathrm{~m}^{3} \mathrm{~s}^{-1}$ range, among five periods having different lengths of time during the years 1904 to 1990, which yields the weighted average of $16800 \mathrm{~m}^{3} \mathrm{~s}^{-1}$. When comparing these values to the LUFM results, the model resolution must be considered. The interval of $13000-17000 \mathrm{~m}^{3} \mathrm{~s}^{-1}$ was detected using discharge classes derived from the yearly time series simulated (one year is the LUFM's time win-

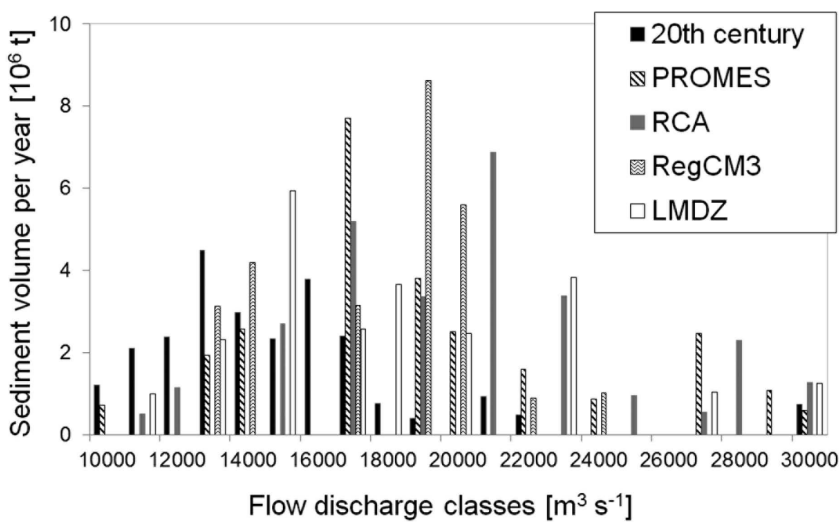

Figure 6. Sediment volume per year from LUFM modelling for corresponding flow discharge classes at Corrientes, characterizing past and future scenarios.

dow), while Amsler et al. (2005) applied monthly records that present larger peaks (maximum monthly discharges in the order of $50000 \mathrm{~m}^{3} \mathrm{~s}^{-1}$ ).

Regarding the resulting morphology, the cross-sections widths appeared with the largest sensitivity to flow regime at the lower Paraná, which exacerbated the deviation between various scenarios in terms of resulting bed profiles and average wetted area. The model gave almost fixed slopes at the lower and middle Paraná for the intervals of around 2$3 \mathrm{~cm} \mathrm{~km}^{-1}$ and $3-5 \mathrm{~cm} \mathrm{~km}^{-1}$, respectively, and mostly depending on the sub-reach location (morphological box), while the corresponding cross-sections changes were also correlated to the variability of forcing time series (scenarios). The river widths at the lower and middle Paraná varied within the range of 1600-3300 $\mathrm{m}$ and $1200-2400 \mathrm{~m}$, respectively.

The resulting bed levels in terms of cumulate variation (i.e. final depositions and erosions at each morphological box) were assessed for the 20th century and the two continuous time series available from future projections (PROMES and RCA scenarios). Despite the noticeable increase in the forcing and effective discharges (Figs. 5 and 6, respectively) when passing from past to future scenarios, the bed level changes along the river maintained almost the same aggradation or degradation tendencies as for the 20th century, with maximal values of a few centimetres within one century (Fig. 7). The bed level result was rather stable along the river, especially at the lower Paraná.

Some morphological data of the Paraná River can be retrieved from the literature: Amsler et al. (2005) and Castro et al. (2007) observed that the same climate variability drove braided and bifurcated patterns of the channel morphology at the middle and lower Paraná, respectively. This difference was ascribed to the alluvial plane morphology change along the river, which noticeably enlarges and degrades downstream. Although these observed channel morphologies may be simulated with detailed 2-D models, the 


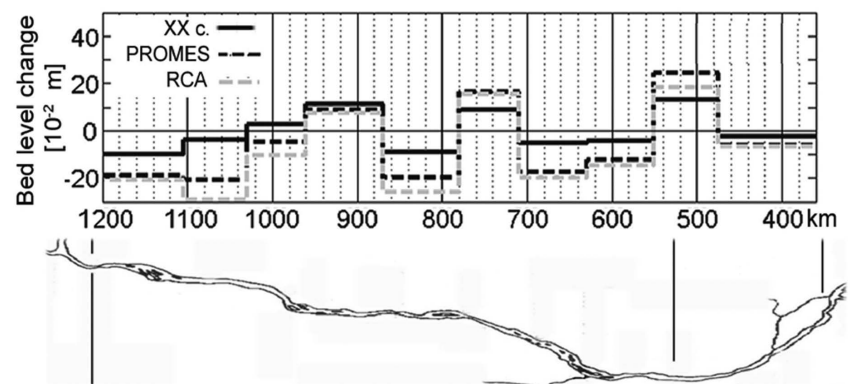

Figure 7. Simulated cumulate variation of the bed level for the continuous time series: past century and 21 st century predictions (PROMES and RCA scenarios).

performed simulations corroborated the argument that river slope and width are almost time-fixed constraints.

\section{Discussion}

The changes in effective discharge, sediment transport rate, riverbed level, bed sediment sorting and cross-section width occurring during the 20th and the 21st centuries along the Zambezi and Paraná rivers were analysed with the LUFM model. This 1-D code introduces some important simplifications in the mathematical description of river hydraulics (among others, kinematic propagation of water flow and local uniform flow hypothesis) and in the schematization of the channel geometry (namely, cross-sections synthetic profile). These simplifications gave some opportunities with respect to more detailed modelling (e.g. 2-D codes). In fact, the LUFM model simulated the long-term morphodynamic processes influenced by natural and anthropogenic pressures at non-detailed spatial and temporal scales by implementing a very basic database. This is particularly relevant for remote parts of the world, such as in the presented case studies.

The performed analyses confirmed that the LUFM model is able to simulate average variations at large temporal and spatial scales (as pointed out by Ronco et al., 2010). As hoped, the schematizations used for the two applications were able to reduce the computational effort and the topographic resolution usually required to implement standard 1-D models and, even more, for detailed 2-D modelling. Notwithstanding the lack of geometrical resolution, the LUFM model responses appeared rather reliable and less sensitive to inaccuracies induced by model parameters calibration on the basis of detailed field data. Indeed, the estimation of induced biases is not trivial, especially for very detailed modelling, which includes a lot of processes parameterization and for long-term simulations that extrapolate to a timeline far from the initial conditions. The operated synthetic description of transversal cross sections, based on satellite images, presents some advantages with respect to occasional surveys. The LUFM model accounted for sediment transport variations due to the active channel modi- fications driven by hydrological changes at seasonal scale (Nones et al., 2013).

Therefore, the simplified model applied presents a potential method to overcome the lack of detailed field data, providing, at the same time, reliable results for a variety of engineering and environmental practices, ranging from long-term sediment management to environmental impact studies. Basic databases (i.e. historical cartography for initial geometry and river stage records for boundary conditions as well as sporadic geomorphological data) are usually also available for remote parts of the world, which noticeably enlarges the model applicability to large rivers with respect to more advanced 2-D codes.

Furthermore, it is worth noting that the simplified modelling of river cross-sections variations refines the code resolution to seasonal oscillation, although the larger evolution window was used for updating the bed profile and sediment sorting, which fulfils the LUF hypothesis. To this end, the additional river width-discharge database is required, which introduces the model's calibration on statistic distributions from a certain period. Indeed, satellite images, historical cartography and river stage records are largely also available for ungauged river basins and date back from decades (for satellite images) to centuries in the cases of historical records and maps.

\section{Conclusions}

Two large rivers were analysed with a simplified 1-D model, which highlights the opportunity for using basic databases to simulate river morphology at low-resolution for remote parts of the world. The proposed 1-D code couples the longitudinal modelling of their riverbeds with a synthetic description of cross-sections shapes and was applied for studying past and future river evolution on the basis of topographic basic data, stage records and satellite images. In addition, future projections were produced from available climate-hydrology scenarios.

The results indicate the potential of non-detailed models for analysing the long-term impact of anthropogenic and natural pressures, especially in the case of rivers located in remote parts of the world, for which detailed field data are usually not available. This potential is a particularly relevant option to 2-D modelling for which results depend on processes parameterization and calibrations based on detailed field data.

In our application to the lower Zambezi River only a topographic and granulometric basic survey was applied to describe the initial morphology, while satellite images and stage records provided river cross-sections shapes and boundary conditions. The impacts of hydropower reservoirs on river morphology during the 20th century were simulated. As highlighted by the cited literature concerning the river's evolution, the results reported here agree with 
the riverbed aggradation and delta erosion observed during the last century.

In the second case study, in addition to basic data, climatehydrology scenarios were used at model boundaries to study the impacts of future climate variability over the middle and lower Paraná. The results reported here corroborate the hypothesis that climate drivers differently affect the channel divagation because of riverbed slope and width decreasing and increasing, respectively, when passing from the middle to the lower Paraná River.

Acknowledgements. This research has received funding from (1) the European Community's Seventh Framework Programme (FP7/2007-2013) under grant agreement no. 212492 (CLARISLPB, a Europe-South America Network for Climate Change Assessment and Impact Studies in La Plata Basin); and (2) the CUIA IT-AR universities consortium under the project "Impatto dei cambiamenti ambientali sull'eco-idromorfodinamica fluviale".

Edited by: J. Turowski

\section{References}

Amsler, M. L., Ramonell, C. G., and Toniolo, H. A.: Morphologic changes in the Parana River channel (Argentina) in the light of the climate variability during the 20th century, Geomorphol., 70, 257-278, 2005.

Amsler, M. L., Drago, E. C., and Paira, A. R.: Fluvial sediments: main channel and floodplain interrelationships, in: The Middle Parana River: limnology of a subtropical wetland, edited by: Iriondo, M., Paggi, J. J., Parma, M. J., Springer, Berlin Heidelberg New York, 123-142, 2007.

Amsler, M. L. and Drago, E. C.: A review of the suspended sediment budget at the confluence of the Parana and Paraguay Rivers, Hydrol. Proc., 23, 3230-3235, 2009.

Attwell, R. I. G.: Some effects of Lake Kariba on the ecology of a floodplain of the mid-Zambezi valley of Rhodesia, Biol. Conserv., 2, 189-196, 1970.

Basson, G.: Hydropower Dams and Fluvial Morphological Impacts-An African Perspective, Paper from United Nations Symposium on Hydropower and Sustainable Development, 2004.

Beilfuss, R. D. and Davies, B. R.: Prescribed flooding and wetlands rehabilitation in the Zambezi Delta, Mozambique, An Int. Perspective on Wetland Rehabilitation, 143-158, 1999.

Beilfuss, R. D., Moore, D., Dutton, P., and Bento, C.: Patterns of vegetation change in the Zambezi Delta, Mozambique, Working paper \#3 of the Program for the Sustainable Management of Cahora Bassa Dam and the Lower Zambezi Valley, International Crane Foundation, USA, 2001.

Biedenharn, D. S., Thorne, C. R., Soar, P. J., Hey, R. D., and Watson, C. C.: A practical guide to effective discharge calculation (Appendix A), US Army Corps of Eng., Vicksburg, Mississippi, USA, 1999.

Bolton, P.: The regulation of the Zambezi in Mozambique: A study of the origins and impact of the Cabora Bassa project, $\mathrm{PhD}$ Thesis. University of Edinburgh, Great Britain, 1983.
Bowmaker, A. P.: A Report on the Kariba Lake Area and Zambezi River Prior to Inundation, and the Initial Effects of Inundation with Particular Reference to the Fisheries Training Centre on Fishery Survey for the Countries of African Region (Report), FAO Library Fiche AN, 59986, Rome, Italy, 1960.

Brown, C. and King, J.: Modifying dam operating rules to deliver environmental flows: experiences from southern Africa, Int. J. River Basin Manage., 10, 13-28, 2012.

Castro, S. L., Cafaro, E. D., Gallego, M. G., Ravelli, A. M., Alarcón, J. J., Ramonell, C. G., and Amsler, M. L.: Evolución morfológica histórica del cauce del río Parana en torno a Rosario (456$406 \mathrm{~km}$ ), Proceedings of the XXI Congreso Nacional del Agua, CONAGUA 2007, Tucumán, Argentina, 2007 (in Spanish).

Chenje, M.: State of the Environment Zambezi Basin, SADC/IUCN/ZRA/SARDC, Maseru/Lusaka, Harare, 2000.

Coulthard, T. J. and Van de Wiel, M. J.: Climate, tectonics or morphology: what signals can we see in drainage basin sediment yields?, Earth Surf. Dynam. Discuss., 1, 67-91, 2013.

Davies, R. D., Beilfuss, R. D., and Thomas, M. C.: Cahora Bassa Retrospective, 1974-1997, effects of flow regulation on the Lower Zambezi River, Limnol. Develop. World, 27, 1-9, 2000.

Di Silvio, G.: Modelli matematici per lo studio di variazioni morfologiche dei corsi d'acqua a lunga e breve scala temporale, Studi e Ricerche, 356A, 1983 (in Italian).

Di Silvio, G. and Peviani, M.: Modelling Short- and Long-Term evolution of mountain rivers, an application to the torrent Mallero (Italy), Lecture Notes in Earth Sciences n. 37, Fluvial Hydraulics of Mountain Regions, edited by: Armanini, A. and Di Silvio, G., Springer Verlag, 1991, 293-315, 1989.

Di Silvio, G.: Review of state-of-the-art research on erosion and sediment dynamics from catchment to coast (a Northern perspective. Meeting of the Task Force Group of ISI (International Sediment Initiative) of UNESCO-IHP (technical report), Paris, France, 2004.

Di Silvio, G. and Nones, M.: Morphodynamic reaction of a schematic river to sediment input changes: Analytical approaches, Geomorphology, in press, doi:10.1016/j.geomorph.2013.05.021, 2013.

Du Toit, R. F.: Some environmental aspects of proposed hydroelectric schemes on the Zambezi river, Zimbabwe, Biol. Conserv., 28, 73-87, 1984.

Dunham, K. M.: Vegetation-environment relations of a Middle Zambezi floodplain, Vegetatio, 82, 13-24, 1989.

Fasolato, G., Ronco, P., and Tregnaghi, M.: Operazioni di sghiaiamento da un serbatoio alpino ed effetti sulla morfodinamica fluviale. Proceedings of the XXX Convegno di Idraulica e Costruzioni Idrauliche - IDRA 2006, Roma, Italy, 2006 (in Italian).

Fasolato, G., Ronco, P., Langendoen, E. J., and Di Silvio, G.: Validity of Uniform Flow Hypothesis in One-Dimensional Morphodynamic Models, Journal of Hydraulic Engineering, ASCE, 37, 183-195, 2011.

Garde, R.J. and Ranga Raju K.G.: Mechanics of sediment transportation and alluvial stream problems, Wiley Eastern Ltd., New Delhi, India, 1977.

Guerrero, M. and Lamberti, A.: Bed-roughness investigation for a 2D model calibration: the San Martìn case study at Lower Paranà, Int. J. Sediment Res., 28, in press, 2013. 
Guerrero, M., Di Federico, V., and Lamberti, A.: Calibration of a 2-D morphodynamic model using water-sediment flux maps derived from an ADCP recording, J. Hydroinformatics, 15, 813828, 2013a.

Guerrero, M., Nones, M., Saurral, R., Montroull, N., and Szupiany, R.N.: Parana River morphodynamics in the context of climate change, International J. River Basin Manage., doi:10.1080/15715124.2013.826234, 2013b.

Guy, P. R.: River bank erosion in the mid-Zambezi valley, downstream of Lake Kariba, Biol. Conserv., 19, 199-212, 1981.

Hall, A., Valente, I., and Davies, B. R.: The Zambezi River in Mozambique, the physicochemical status of the Middle and Lower Zambezi prior to the closure of the Cabora Bassa Dam, Freshwater Biol., 7, 187-206, 1977.

Hidroeléctrica de Cahora Bassa (HCB): Technical Reports on Cahora Bassa Project, Songo, Mozambique, 2004.

Hirano, M.: River bed degradation with armouring.Transaction of Japanese Society of Civil Engineering, 3, 194-195, 1971

Hughes, R. H. and Hughes, J. S.: A Directory of African Wetlands, IUUCN/UNEP/WCMC, Gland, Switzerland, ISBN 288032-949-3, 1992.

Latrubesse, E.: Patterns of Anabranching channels, the ultimate end-member adjustments of mega-rivers, Geomorphology, 101, 130-145, 2008.

Leopold, L. B. and Maddock Jr., T.: The Hydraulic Geometry of Stream Channels and Some Physiographic Implications, Geol. Survey Paper, 252 pp., 1953.

Leopold L. B. and Wolman M.G.: River Channel Patterns: Braided, Meandering and Straight, US Geol. Survey Prof. Paper, 282 pp., 1957.

Main, M.: Zambezi, Journey of a River. Southern Book Publishers, Halfway House, South Africa, ISBN 1-86812-257-3, 1992.

McCartney, M., Cai, X., and Smakhtin, V.: Evaluating the Flow Regulating Functions of Natural Ecosystems in the Zambezi River Basin, 2013.

Nones, M., Bonaldo, D., Di Silvio, G., and Guarino, L.: Sediment budget of rivers at watershed scale: the case of Adige River. EGU General Assembly Conference Abstracts, 11, p. 1197, 2009.

Nones, M.: Riverine dynamics at watershed scale: hydro-morphobiodynamics in rivers, Eds. LAP Lambert Academic Publishing, p. 140, ISBN-13: 978-3659367854, 2013.

Nones, M., Ronco, P., and Di Silvio, G.: Modelling the impact of large impoundments on the Lower Zambezi River. Int. Journal of River Basin Management 11(??), 221-236, 2013.

Parker, G. P., Wilcock, P. R., Paola, C., Dietrich, W. E., and Pitlick, J.: Physical basis for quasi-universal relations describing bankfull hydraulic geometry of single-thread gravel bed rivers, J. Geophys. Res., 112, F04005, doi:10.1029/2006JF000549, 2007.

Reeve, W. H.: Progress and Geographical Significance of the Kariba Dam, The Geograph. J., 126, 140-146, 1960.
Ronco, P.: Sediment Budget of Unsurveyed Rivers at Watershed Scale: the Case of Lower Zambezi. PhD Thesis. University of Padova, Italy, http://paduaresearch.cab.unipd.it/625, 2008.

Ronco, P., Fasolato, G., and Di Silvio, G.: Modelling evolution of bottom profile and grainsize distribution in unsurveyed rivers, Int. J. Sed. Res., 24, 127-144, 2009.

Ronco, P., Fasolato, G., Nones, M., and Di Silvio, G.: Morphological effects of damming on lower Zambezi River, Geomorphology, 115, 43-55, 2010.

Saurral, R., Montroull, N., and Camilloni, I.: Development of statistically unbiased 21st century hydrology scenarios over La Plata Basin, Accepted by International Journal of River Basin Management, 2013.

Scodanibbio, L. and Mañez, G.: The World Commission on Dams: A fundamental step towards integrated water resources management and poverty reduction? A pilot case in the Lower Zambezi, Mozambique, Phys. Chem. Earth, 30, 976-983, 2005.

Singh, V. P.: On the theories of hydraulic geometry, Int. J. Sed. Res., 18, 196-218, 2003.

Suschka, J. and Napica, P.: Ten years after the conclusion of Cabora Bassa Dam, The impacts of large water projects on the environment, Proceedings of an international symposium, UNEP/UNESCO, Paris, France, 1986.

Tilmant, A., Kinzelbach, W., Juizo, D., Beevers, L., Senn, D., and Casarotto, C.: Economic valuation of benefits and costs associated with the coordinated development and management of the Zambezi river basin, Water Policy, 14, 490-508, 2012.

Timberlake, J.: Biodiversity of the Zambezi basin wetlands, review and preliminary assessment of available information, Final Report IUCN, Harare, Zimbabwe, 1998.

Walford, H. L., White, N. J., and Sydow, J. C.: Solid sediment load history of the Zambezi Delta, Earth Planet. Sci. Lett., 238, 49-63, 2005.

Walling, D. E.: The sediment yields of African rivers. Challenges in African Hydrology and Water Resources, Proceedings of the Harare Symposium, IAHS Publ., 144, 265-283, 1984.

Wilkerson, G. V. and Parker, G.: Physical Basis for Quasi-Universal Relations Describing Bankfull Hydraulic Geometry of Sand-Bed Rivers, J. Hydraul. Engin., 137, 739-753, 2011.

Williams, R. D., Brasington, J., Hicks, M., Measures, R., Rennie, C. D., and Vericat, D.: Hydraulic validation of twodimensional simulations of braided river flow with spatially continuous aDcp data, Water Resour. Res., 49, 5183-5205, doi:10.1002/wrcr.20391, 2013.

Yalin, M. S.: River mechanics, Eds. Pergamon Press, Oxford, England, 1992 